\title{
General Psychiatry Rare case report of Van Gogh syndrome in a patient with paranoid schizophrenia
}

To cite: Mudgal V, Rastogi $P$, Niranjan V, et al. Rare case report of Van Gogh syndrome in a patient with paranoid schizophrenia. General Psychiatry 2020;33:e100095. doi:10.1136/ gpsych-2019-100095

Received 29 May 2019 Revised 07 August 2019 Accepted 01 September 2019

Check for updates

(C) Author(s) (or their employer(s)) 2020. Re-use permitted under CC BY-NC. No commercial re-use. See rights and permissions. Published by BMJ.

Department of Psychiatry, MGM Medical College, Indore, Madhya Pradesh, India

Correspondence to Dr Varchasvi Mudgal, Psychiatry, M.G.M Medical College, Indore, M.P, India;

varchasvimudgal04@gmail.com

\author{
Varchasvi Mudgal (D), Pali Rastogi, Vijay Niranjan, Ramghulam Razdan
}

\begin{abstract}
Self-mutilation is often associated with psychiatric disorders. We describe here a 22-year-old male Indian with decreased sleep, aggressive behaviour, self-muttering, disorganised behaviour, frequent spitting, biting and self-mutilation; he bit off his right ring finger and left thumb (Van Gogh syndrome). Self-harm behaviour was frequently evidenced by family members resulting in various injuries. The patient was diagnosed with paranoid schizophrenia and was treated with anti-psychotics which resulted in a decrease in his behavioural disturbances along with treatment for his self-mutilation injuries. Here we discuss Van Gogh syndrome's presentation of selfmutilation in paranoid schizophrenia and its implications.
\end{abstract}

\section{INTRODUCTION}

Conceivably Van Gogh is the first name to ring in our minds if we hear about 'self-inflicted mutilation.' Vincent van Gogh was a notable post impressionist painter who self-mutilated his ear. He cut-off his left ear and gave it to a sex worker to take care of it. This incident has led to what has been called the Van Gogh syndrome which has now become a synonym for self-mutilation, particularly referring to amputation of a bodily extremity. ${ }^{1}$

Self-mutilation of various sorts may occur in a few individuals with schizophrenia. Regardless of the act, self-injury is different from a suicide attempt in that death is not the conscious goal, hence termed non-suicidal self-injury. In individuals with psychosis, it is typically due to a delusional belief or in response to imperative auditory hallucinations or made phenomenon. ${ }^{23}$

Sometimes, especially among psychotic inpatients, eye, tongue, ear, extremities or genital self-mutilations have been reported. ${ }^{4}$ Self-injury is the intentional and direct injury to self that includes bite, burn, ulceration and headbanging. These injuries are rarely fatal and are usually not suicidal in nature. Bipolar disorder, drug abuse, Munchausen's syndrome and metabolic syndromes like Lesch-Nyhan syndrome where compulsive self-mutilation may be seen are often associated with this disorder. ${ }^{56}$ Studies have shown that about $4 \%$ of hospitalised psychiatric patients attempt self-mutilation. ${ }^{7}$
Major self-mutilation is most commonly associated with severe psychopathology. Patients with a history of self-harm have significantly greater symptoms of depression, greater suicidal thoughts, increased number of hospital admissions and greater duration of illness, compared with patients without a history of self-harm. ${ }^{8}$

\section{CASE HISTORY}

We report on a male patient aged 22 years from the psychiatry department of MGM Medical College, Indore, India. About 6 months ago he developed decreased sleep after which he had self-muttering behaviour, aggressiveness towards family members and neighbours, frequent spitting, social withdrawal, disorganised behaviour and poor self-care, along with self-mutilating behaviour in which he bit off the distal end of his right ring finger and terminal end of the left thumb. The wounds were of lacerated type and measured $1.5 \times 1 \times 0.8 \mathrm{~cm}$ in the right ring finger (figure 1 ) and $1.8 \times 1.1 \times 0.7 \mathrm{~cm}$ approximately in the left thumb. He frequently tried to injure himself by drinking acid, jumping from the roof of his house, jumping off from moving vehicles and going into the middle of a swamp. Due to the self-injurious behaviours the patient sustained a few minor injuries as well, including abrasions on the arm and legs, mild burn on his chest due to acid ingestion, and so on. The reason for consultation was self-mutilation behaviour of the patient prior to which the family resorted to faith healing. The patient was immediately assessed and his wounds were managed in the hospital by a surgeon, and was advised to have regular follow-up. He continued his spitting behaviour and tried to bite the treating physician and other staff members.

The patient had no history of psychiatric illness or instances of self-injury. Family history was suggestive of schizophrenia like illness of his mother for 25 years without any self-mutilation behaviour, and his brother had a depression episode without suicidality 


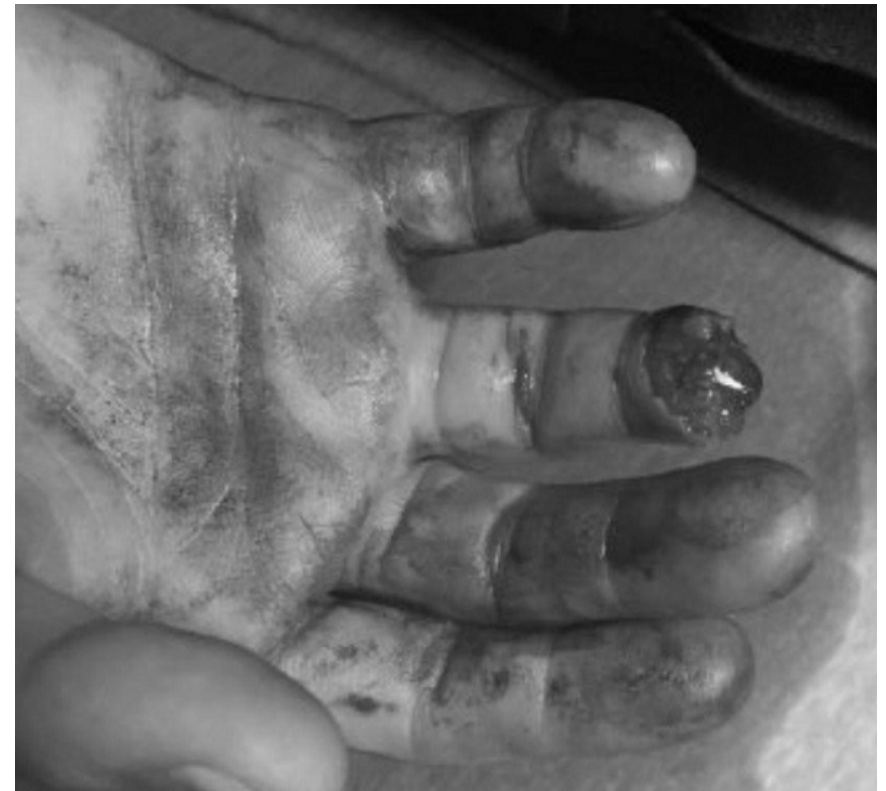

Figure 1 The patient self-mutilated his right ring finger due to made phenomenon and auditory hallucination which was the primary psychopathology in a case of paranoid schizophrenia; the injury mandated immediate medical intervention and was managed by surgical support.

or self-harm after the death of his sister. Within family members, interpersonal relations were cordial. There was no history of self-harm/mutilation in any other family member. Personal history revealed that the patient was full-term normal delivery with appropriate developmental milestones; childhood and adolescent period was unremarkable excluding a few instances of fights with peers; he had no history of childhood abuse or neglect. The patient was a farmer by occupation; sexual history was unremarkable; and had substance use of tobacco in the past 3 years and cannabis (ganja) for 2 years in dependence pattern. There were no significant withdrawal symptoms other than irritability. Cannabis and tobacco intake was persistent until onset of illness.

Premorbid personality of the patient was normal; he actively participated in social events and had a positive attitude towards responsibilities and duties; mood was predominantly cheerful and he had interests in music and going on trips with friends. No borderline personality traits or impulsive traits were elicited.

Physical examination-pallor present, burn over right side of chest extending from second rib mid-sternal line to fifth rib mid-clavicular line, amputation of distal phalanx of right ring finger and left thumb. Blood pressure was $112 / 84 \mathrm{~mm} \mathrm{Hg}, \mathrm{SpO}_{2} 98 \%$, pulse $82 \mathrm{bpm}$, bilateral chest clear, no added sounds heard, no significant finding per abdomen and central nervous system examination revealed no abnormality.

On mental status examination, the patient's general appearance and behaviour were unkempt and untidy, eye contact was established and not sustained, posture was normal, and facial grimacing and frequent spitting were present. The patient displayed an uncooperative attitude. His speech was hesitant, relevant, coherent and had normal intensity, a monotonous quality and decreased productivity. Affect was blunted, constricted with restricted range; subjectively mood was depressed, decreased reactivity and communicability. The patient reported slowing of thoughts, but there was no formal thought disorder detected in the serial mental examination. Possession component of thought presented with obsessions and compulsion of spitting, ideas of guilt, delusions of control, delusions of persecution, delusional perception and second and third-person auditory hallucinations which were imperative; somatic passivity was elicited along with made impulses. The patient explained that the spirit of his pet horse, which had died a few months ago, is now haunting him and controlling his body and impulses resulting in motor control, passivity and frequent spitting. Judgement was impaired and insight was grade 3 out of 6 .

All routine investigations were normal including complete blood counts, liver and renal functions, electrolytes, electroencephalogram (EEG) and CT scan, with uric acid levels being within normal limits, except neutrophilia and lymphocytosis during febrile episode secondary to wounds which during the course returned to normal.

Brief Psychiatric Rating Scale ${ }^{9}$ score was 58/128 indicating psychosis. Hamilton Depression Rating Scale ${ }^{10}$ score was $4 / 52$ while Young Mania Rating Scale ${ }^{11}$ score was $8 / 60$ pointing against the differentials of bipolar illness or major depression.

A provisional diagnosis of paranoid schizophrenia was made after serial mental status examination and presence of first rank symptoms using the International Classification of Diseases-10 classification of mental and behavioural disorders. ${ }^{12}$

Injectable haloperidol $10 \mathrm{mg}$ and promethazine $50 \mathrm{mg}$ intramuscular per day were continued for the first 10 days, then the patient was started on risperidone $2 \mathrm{mg}$ oral for psychosis; for sleep disturbance, quetiapine $100 \mathrm{mg}$ at bedtime was given. Management of the wound was done using debridement and stitches along with antibiotics and analgesics on the day of admission. Response to the initial dose of anti-psychotic was poor due to which risperidone was gradually hiked to $8 \mathrm{mg}$ in 4 weeks; due to occasional violent outbursts, injectables were kept on an as-needed basis along with regular dressing of the wounds. The patient was kept on risperidone and quetiapine tablets, which resulted in good response in terms of disorganised behaviour, aggression, self-mutilation and frequent spitting. On continuing the regimen for 8 weeks, the symptoms remitted and mutilation wounds were healed with conventional treatment and regular surgical supervision.

\section{DISCUSSION}

Self-mutilation behaviour, although common in bipolar disorder, substance abusers and Munchausen's syndrome, is still an uncommon occurrence in 
schizophrenia. We report a case of self-mutilation in schizophrenia. After detailed assessment, an initial provisional diagnosis of paranoid schizophrenia was formulated because of the typical presentation and presence of first rank symptoms, including auditory hallucinations and delusions of control, somatic passivity along with made impulses. Lesch-Nyhan syndrome was ruled out with serum uric acid which was found to be normal. Review of premorbid personality helped in ruling out self-harm secondary to borderline personality; cannabisinduced psychosis became an unlikely differential due to non-decrease in psychopathology despite abstinence for almost 6 months. Organic psychosis non-convulsive epilepsy states were ruled out using CT scan and EEG. The self-mutilation behaviour in schizophrenia was considered to be due to the impulses occurring in the patient due to the primary psychopathology of schizophrenia, which has been reported less frequently in the literature as the Van Gogh syndrome, especially in context of schizophrenia. To the best of our knowledge, the treatment of such cases is scarce in research literature and the management of these patients had been done by treatment of the underlying schizophrenia using standard guidelines. The effectiveness of the first and second-generation anti-psychotic drugs is equivalent, but their adverse reactions are revealed in different aspects. Therefore, the precise prediction of antipsychotic drugs' adverse reaction is probably a feasible option for the current precise treatments for schizophrenia. ${ }^{13}$ Such patients can pose a novel challenge for psychiatrists and nursing staff alike hence requiring a tailored management plan. Behavioural, pharmacological and psychotherapeutic interventions are required in such patients to meet their needs. We urge to keep a differential of schizophrenia in cases of self-mutilation along with other common disorders.
Acknowledgements This case report was made with contribution from the patient and his brother who were the informants. Their efforts and patience for the same are deeply appreciated.

Funding The authors have not declared a specific grant for this research from any funding agency in the public, commercial or not-for-profit sectors.

Competing interests None declared.

Patient consent for publication Obtained.

Provenance and peer review Not commissioned; externally peer reviewed.

Open access This is an open access article distributed in accordance with the Creative Commons Attribution Non Commercial (CC BY-NC 4.0) license, which permits others to distribute, remix, adapt, build upon this work non-commercially, and license their derivative works on different terms, provided the original work is properly cited, appropriate credit is given, any changes made indicated, and the use is non-commercial. See: http://creativecommons.org/licenses/by-nc/4.0/.

ORCID iD

Varchasvi Mudgal http://orcid.org/0000-0002-7078-6710

\section{REFERENCES}

1 Burgess JW. Relationship of depression and cognitive impairment to self-injury in borderline personality disorder, major depression, and schizophrenia. Psychiatry Res 1991;38:77-87.

2 Dworkin RH. Pain insensitivity in schizophrenia: a neglected phenomenon and some implications. Schizophr Bull 1994;20:235-48.

3 Pourafkari N. Farhange moaser, volume 2. Nobahar, 1373: 1336.

4 Baguelin-Pinaud A, Seguy C, Thibaut F. Self-Mutilating behaviour: a study on 30 inpatients. Encephale 2009;35:538-43.

5 Roka YB, Thapa R, Puri PR, et al. Van Gogh syndrome. J Nepal Health Res Counc 2011;9:79-81.

6 Kaplan HI, Sadock BJ. Comprehensive textbook of psychiatry; volume 1. 7th edn. New York: Sadock V.A, 2000: 817.

7 Kaplan HI, Sadock BJ. Synopsis of psychiatry. 8th edn. New York: Courtney Milet; 1998, 1791: 869-70.

8 Simms J, McCormack V, Anderson R, et al. Correlates of selfharm behaviour in acutely ill patients with schizophrenia. Psychol Psychother 2007;80:39-49.

9 Overall JE, Gorham DR. The brief psychiatric rating scale. Psychol Rep 1962;10:799-812.

10 Young RC, Biggs JT, Ziegler VE, et al. A rating scale for mania: reliability, validity and sensitivity. Br J Psychiatry 1978;133:429-35.

11 Hamilton M. A rating scale for depression. J Neurol Neurosurg Psychiatry 1960;23:56-62.

12 World Health Organization. The ICD-10 classification of mental and behavioural disorders: clinical descriptions and diagnostic guidelines. Geneva: World Health Organization, 1992.

13 Zhang C, Mao Y, Song L. Precise treatments for schizophrenia: where is the way forward? Gen Psychiatr 2018;31:e000002.

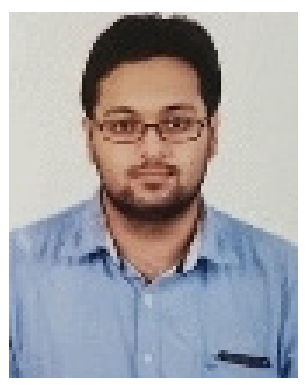

Dr. Varchasvi Mudgal is a third year post graduate resident at M.G.M Medical College Indore, M.P affiliated to MPMS University Jabalpur, M.P, India. He completed his bachelor's degree of M.B.B.S from Pt.J.N.M Medical College affiliated to Ayush Health University in Raipur, C.G, India. He is currently working as an academic resident in a multispeciality hospital associated with a tertiary mental hospital and de-addiction centre. His main research interests include depression, suicide, substance use disorder, consultation liaison. 